\title{
When Does Similar Mean the Same: A Case for Relaxing Standards of Substantial Equivalence in Genetically Modified Food Crops
}

\author{
Stephen L. Love ${ }^{1}$ \\ University of Idaho, Aberdeen Research and Extension Center, Aberdeen, ID 83210-0530
}

\begin{abstract}
Plant genetic engineering is rapidly moving from theory to application. Transgenic tomatoes (Lycopersicon esculentum Mill.), potatoes (Solanum tuberosum L.), cotton (Gossypium hirsutum L.), corn (Zea mays L.), soybeans [Glycine max (L.) Merrill], and other crop plants are now being commercially produced and sold. As useful genes are identified and technical knowledge is advanced, an expanding number of crop plants will be genetically modified. This technology has the potential to help solve numerous production and marketing problems common to horticultural crops. Unfortunately, the high cost of developing genetically engineered cultivars may limit the use of this technology in minor-use horticultural crops. These costs come from numerous developmental activities, including basic genetic research, field testing, meeting regulatory requirements, marketing, and public relations work. Improving almost any crop is technically possible; however, unless these costs are minimized, neither private companies nor publicly funded research programs will be able to afford to use these genetic advances for improvement of most horticultural crops. Thus, this technology will not help the majority of horticultural producers solve problems and meet increasingly stringent environmental policies.
\end{abstract}

Meeting federally mandated regulations for food and environmental safety is one of the major costs of developing genetically modified cultivars. The content of these regulations is still in a state of flux. In the future, they may become more stringent, or may be modified, or even removed, as definitive data and experience show safety issues to be of little or no concern to the public. This latter trend is already occurring with respect to field testing and production. Over the past several years, field testing has become much simpler as the U.S. Dept. of Agriculture/ Animal and Plant Health Inspection Service (APHIS) and the Environmental Protection Agency (EPA) have relaxed standards for handling genetically engineered plant materials. However, food safety-related

Received for publication 23 July 1999. Accepted for publication 22 Nov. 1999. Manuscript number 99717 of the Idaho Agricultural Experiment Station. The cost of publishing this paper was defrayed in part by the payment of page charges. Under postal regulations, this paper therefore must be hereby advertisement solely to indicate this fact.

${ }^{1}$ Research Professor. E-mail address: slove@ uidaho.edu regulations have remained as strict or stricter than those initially adopted.

In the United States, three federal agencies are responsible for regulating genetically modified organisms, APHIS, EPA, and the Food and Drug Administration (FDA). The role of APHIS, under the Plant Quarantine Act, is to ensure that modified organisms do not become weedy or pestilent. The EPA regulates only organisms that have pesticidal activity and assures environment safety with respect to the specific pesticidal gene product. The FDA becomes involved if a modified organism is to be used as food and oversees all food safety issues. It is responsible for determining that foods from genetically modified crops are both safe and nutritionally adequate. In Canada, Health and Welfare Canada is responsible for regulating all aspects of genetically modified organisms destined for food use. Agriculture Canada regulates organisms associated with agriculture that are not destined for food use. This paper discusses a concept known as substantial equivalence as it relates to safety and nutrition, and consequently, includes the areas of regulation that fall under the jurisdiction of FDA and Health and Welfare Canada.

Substantial equivalence is the concept established by a joint committee of the Food and Agricultural Organization (FAO) and World Health Organization (WHO) and adopted by regulatory agencies in the United States and Canada, as well as in Europe, as a guide to assess the safety status of food crops developed via biotechnology (FAO/WHO, 1991). In current practice, establishing substantial equivalence involves confirmation that nutritional composition (meaning natural toxicants and nutritional components) of genetically modified food crops is similar to or identical with that of the original, unaltered crops from which they were derived. Because introduction of cultivars of genetically modified crops into the food chain is a recent phenomenon, procedures to be used in establishing substantial equivalence are still being developed. This evolution includes both identification of acceptable comparatives and generation of lists of key compositional constituents.

A $1991 \mathrm{FAO} / \mathrm{WHO}$ report states that, "Biotechnology has a long history of use in food production and processing. It represents a continuum embracing both traditional breeding techniques and the latest techniques based on molecular biology. The newer biotechnological techniques, in particular, present great possibilities for rapidly improving the quantity and quality of food available. The use of these techniques does not result in food which is inherently less safe than that produced by conventional means." Assuming this is true, there should be little concern for the safety of foods derived from genetically modified plants. However, caution is wise when utilizing any new technology. For this reason, confirming food safety is a critical part of the science of creating improved plant cultivars through biotechnology, especially in the early stages of consumer acceptance. However, certain elements of the current use of the substantial equivalence concept add extensive developmental costs to genetically modified food crops. The present interpretation of substantial equivalence dictates that the level of any measurable constituent in a genetically modified cultivar must be similar or equal to that in the cultivar from which it was derived. Under this definition, there is no limit to the number of constituents that must be measured. For any crop the number that could be considered nutritionally and toxicologically important is immense. If plants from every transformation event must be analyzed for every imaginable constituent, using samples from multiple sites and years, developmental costs will skyrocket. For this reason, a balance must be struck between ensuring food safety and holding costs to a level that allows this technology to add to food availability. The immediate need is to answer two important questions about establishing substantial equivalence: 1) What is the appropriate comparative standard within a crop? 2) What are the critical constituents to be analyzed for any given crop?

I believe that the concept of substantial equivalence is an appropriate one for evaluating genetically modified crop plants, if substantial equivalence is appropriately defined. Establishing substantial equivalence for specific prioritized constituents of genetically modified cultivars is important. For each crop these critical constituents will differ. The thesis of this paper is that application of standards for establishing substantial equivalence should be similar to guidelines historically used in traditional breeding and that a limited number of important constituents can be predetermined for most crops. Having had considerable experience with potatoes, I will use this crop as an example, to illustrate the principles I feel should dictate the determination of substantial equivalence. 


\section{EARLY PROCEDURAL PRECEDENCE}

Early efforts to establish substantial equivalence for genetically modified potatoes were closely scrutinized by both research groups and regulatory agencies. Consequently, evaluations were thorough and included over 20 biochemical constituents (Lavrik and Love, 1994). Also, only the original cultivar from which the genetically modified cultivars were derived was used for comparison. Constituents compared included not only nutritional and toxicological components, but also agronomic characteristics and measures of processing quality. Compositional constituents analyzed in these early studies included total solids, glycoalkaloids, sugars, proteins, vitamin $\mathrm{C}$, fats, ash, dietary fiber, thiamine, pyridoxine, folic acid, niacin, riboflavin, calcium, copper, iron, iodine, magnesium, phosphorus, potassium, sodium, and zinc. This early work set a precedent for subsequent procedures and resulted in expectations by regulatory agencies that each genetically modified cultivar be exactly equal to its original counterpart for all of these constituents. This resulted in a situation wherein requirements, with respect to the definition of equivalence, are above what may actually be necessary given the FAO/ WHO guidelines for establishing substantial equivalence. These guidelines state, "The product to be assessed is the food plant and, more specifically, those parts of it that will be consumed. The standard used for purposes of comparison must be the traditional plant or food." (FAO/WHO, 1991). With regard to potatoes, the "traditional plant or food" is an aggregate of hundreds of traditionally bred cultivars. If this is considered, using as the only acceptable comparison equivalence to the original cultivar is more stringent than is dictated by the above guidelines. Also, potatoes are not an important source of many of the constituents currently being measured, meaning small changes in content will not meaningfully alter the quality of the overall food supply.

\section{CONCEPT OF EQUIVALENCE IN TRADITIONAL BREEDING}

Almost 200 potato cultivars are currently produced and sold in the United States, Canada, and Europe. They vary for any given trait, including concentrations of nutritional constituents and natural toxicants. This variability has been largely ignored by breeders, entirely ignored by consumers and regulatory agencies, and is considered normal for the species. Thus, the standard for acceptability in traditionally bred cultivars is much looser than for those derived from biotechnology. Thus, genetically modified cultivars, having concentrations of key constituents that are within the range expressed by these commercially produced cultivars (rather than being identical to the cultivar from which they originate) should be considered substantially equivalent. Adopting this concept as part of the definition of substantial equivalence will provide some flexibility in the process of cultivar improvement through biotechnology, with little or no change in the nutritional value of the overall potato food crop.

A review of 257 release documents for North American potato cultivars revealed very little reliance on nutritional constituents as selection criteria or as a basis for release (see references cited in Chase, 1992). There are two exceptions. One is for a group of compounds called glycoalkaloids, natural toxicants with known mammalian toxicity for which a voluntary ceiling has been established (Sinden, 1991). Glycoalkaloid concentration was documented in $31 \%$ of the total release documents and in nearly all documents published since 1973. The second constituent is total tuber solids, measured as tuber dry matter or estimated from measurement of tuber specific gravity. Total solids is an important quality factor and the most important determinant of culinary appeal in potatoes (Murphy et al., 1967). Dry matter content is documented in nearly all release documents published since 1958 and in many as early as 1935 (see references cited in Chase, 1992).

Information on only four other nutritional constituents has been published in release documents of traditionally bred cultivars, despite the fact that a much longer list is required on consumer packages (Pennington and Wilkening, 1997). These are reducing sugars (glucose and fructose), sucrose, protein, and vitamin $\mathrm{C}$, and were listed in less than $3 \%$ of release documents. In each case, this information was included as part of the cultivar description, not as evidence of value or acceptability.

Within each constituent, concentrations published in release documents varied widely among cultivars (Table 1) (see references cited in Chase, 1992). The natural variability was even greater among potato breeding clones that we have evaluated at the Univ. of Idaho since 1978 for the Western Regional Coordinating Committee (WCC-27), a group of potato breeders in the western United States (Table 1). Breeders consider this variability to be normal, natural, and acceptable.
The range of variability for these same constituents among genetically modified potatoes derived from a single cultivar falls within much narrower confines. This is demonstrated by a summary of 1992 trials with 'Russet Burbank' derived clones transformed with a Bacillus thuringensis gene (Table 2). There were slight differences among the clones for several constituents, probably because of insertion effects, somaclonal variation, or unknown causes, but the range was very narrow when compared to that for genetically dissimilar cultivars.

Historical precedence from past cultivar development work tends to support using varietal range for substantial equivalence comparisons rather than equivalence within a single cultivar. This precedent lends credence to a broader definition for the concept of substantial equivalence. However, there is one argument for requiring an original cultivar and its genetically modified counterparts to be virtually identical for some constituents. The compositional nature of each potato cultivar determines its usefulness for the preparation of specific in-home or industrially processed food products. Within the potato industry, lists are maintained of cultivars acceptable for certain products (Talburt, 1975). If a genetically modified cultivar is substantially different from its original counterpart, but is sold under the same name, difficulties may arise for consumers or some segments of the potato industry. For potatoes, the constituents for which changes are most likely to create problems (because they are critical components of product quality) are total solids and reducing sugar content.

\section{IMPORTANT NUTRITIONAL AND BIOCHEMICAL CONSTITUENTS}

The FAO/WHO guidelines for safety assessment of genetically modified cultivars contain recommendations that compositional analyses focus on constituents that are of major nutritional importance. A quote from the guidelines reads, "Whenever changes are made in the process by which a food is made or a new process is introduced, the implications for the safety of the product should be examined. The scope of the examination will depend on the nature of the perceived con-

Table 1. Ranges of concentrations of nutritional and toxicological constituents of potato cultivars as published in release documents and as evaluated for the Western Regional Coordinating Committee (WRCC-27) from 1978-1997.

\begin{tabular}{|c|c|c|c|c|}
\hline \multirow[b]{2}{*}{ Constituent } & \multicolumn{2}{|c|}{ Release Documents $^{\mathrm{z}}$} & \multicolumn{2}{|c|}{ WRCC-27 Data ${ }^{y}$} \\
\hline & Minimum & $\overline{\text { Maximum }}$ & Minimum & Maximum \\
\hline$\overline{\text { Glycoalkaloids }\left(\mathrm{mg} \cdot \mathrm{kg}^{-1} \mathrm{FWB}\right)^{\mathrm{x}}}$ & 5.0 & 180.0 & 4.0 & 432.0 \\
\hline Total solids $(\%)$ & 15.5 & 26.1 & 15.2 & 27.2 \\
\hline Reducing sugars $(\% \text { DWB })^{\mathrm{w}}$ & 0.10 & 1.20 & 0.01 & 1.70 \\
\hline Sucrose $(\% \text { DWB })^{\mathrm{w}}$ & 0.31 & 0.71 & 0.11 & 1.20 \\
\hline Protein $(\% \mathrm{DWB})^{\mathrm{w}}$ & 6.3 & 9.6 & 2.5 & 10.0 \\
\hline Vitamin $\mathrm{C}\left(\mathrm{mg} \cdot \mathrm{kg}^{-1} \mathrm{FWB}\right)^{\mathrm{x}}$ & 149.0 & 350.0 & 100.0 & 329.0 \\
\hline
\end{tabular}

${ }^{2}$ Derived from potato release documents listed in Chase, 1992.

yTaken from reports of the Western Regional Potato Variety Trials, 1978-97, Aberdeen Research and Extension Center, Univ. of Idaho, Aberdeen.

${ }^{x}$ FWB indicates measurements made on a fresh-weight basis.

wDW indicates measurements made on a dry-weight basis. 
Table 2. Ranges of concentrations of nutritional and toxicological constituents of genetically modified 'Russet Burbank' potato clones. Data from six trials in Idaho, Washington, Wisconsin, Oregon, and Maine, conducted in $1992 .^{\mathrm{z}}$

\begin{tabular}{|c|c|c|c|}
\hline Constituent & Minimum & Maximum & Standard error \\
\hline Glycoalkaloids $\left(\mathrm{mg} \cdot \mathrm{kg}^{-1} \mathrm{FWB}\right)^{\mathrm{y}}$ & 55.0 & 94.0 & 14.0 \\
\hline Total solids $(\%)$ & 19.5 & 20.5 & 1.0 \\
\hline Reducing sugars $(\% \mathrm{DWB})^{\mathrm{x}}$ & 0.18 & 0.21 & 0.02 \\
\hline Sucrose $(\% \text { DWB })^{x}$ & 0.11 & 0.13 & 0.02 \\
\hline Protein $(\% \text { DWB })^{\mathrm{x}}$ & 4.6 & 5.0 & 1.1 \\
\hline Vitamin $\mathrm{C}\left(\mathrm{mg} \cdot \mathrm{kg}^{-1} \mathrm{FWB}\right)^{\mathrm{y}}$ & 85.0 & 96.0 & 4.0 \\
\hline
\end{tabular}

zTaken from Lavrik and Love, 1994.

${ }^{y} \mathrm{FWB}$ indicates measurements made on a fresh-weight basis.

${ }^{x}$ DWB indicates measurements made on a dry-weight basis.

cerns." (FAO/WHO, 1991). Those concerns are for both safety and nutritional issues. It follows that evaluations should include major toxicants and nutrients, but not extend beyond these constituents unless there is strong evidence to suggest the genetic alteration can or will influence other important traits.

Considering these recommendations, along with the historical perspective of cultivar development and the arguments for maintaining cultivar identity, a list of critical constituents and appropriate comparisons for those constituents can be compiled. These constituents can be categorized as essential, important, or desirable for determination of substantial equivalence, depending on the basis of the comparison. For potatoes, the one group of constituents in the essential category is glycoalkaloids, those in the important category are total solids and sugars (reducing sugars and sucrose), and the desirable category includes protein and vitamin $\mathrm{C}$. Justification for identifying these as key constituents and for their categorization of importance will comprise the remainder of this paper.

\section{Potato constituents for which comparison is considered essential}

Steroidal glycoalkaloids, a class of naturally occurring toxins found in most Solanum species, including potato, have been documented as the cause of many cases of human poisoning (Zitnak, 1977). Because glycoalkaloids are a distinct threat to human health, their content in new potato cultivars is carefully analyzed and documented. Breeders in North America use $200 \mathrm{mg} \cdot \mathrm{kg}^{-1}$ of tuber tissue based on fresh weight (FW) as a limit for new cultivars (Sinden, 1991). Mild discomfort or illness can occur in some individuals after eating one large potato with concentrations as low as $280 \mathrm{mg} \cdot \mathrm{kg}^{-1}$ on a fresh weight basis (FWB). Van Gelder (1991) stated, "The SGA (steroidal glycoalkaloids) in potatoes which are considered normal and those which are believed to be potentially toxic to humans differ by a factor of 2 to 3 . This margin is extremely narrow compared to margins that are usually established in food science, especially in view of the many factors that lead to a considerable accumulation of SGA's. It is recommended that the ingestion by the public of the overall amount of SGA's from the various Solanaceae food crops should not be allowed to rise. In this respect, the National Institute of Agricultural Botany (NIAB) at Cambridge, United Kingdom, has recently presented a mean level for solanidine glycosides of $60 \cdot \mathrm{kg}^{-1}$ (equal to $6 \mathrm{mg} \cdot \mathrm{kg}^{-1}$ ) fresh unpeeled potato as a guideline for breeders to bear in mind when submitting new cultivars for national list testing."

The genetic tendency for expression of glycoalkaloids is complicated by environmentally induced variability. An example of this phenomenon is the variability within the Russet Burbank cultivar when grown under a range of environmental conditions, as documented in our laboratory at the Univ. of Idaho. This most widely grown cultivar in the United States and Canada typically expresses glycoalkaloid concentrations in the range of 40-90 $\mathrm{mg} \cdot \mathrm{kg}^{-1}$ (FWB). However, we have measured tuber samples with concentrations as low as 20 and as high as $400 \mathrm{mg} \cdot \mathrm{kg}^{-1}$ (FWB). This magnitude of variability is not uncommon for many cultivars in commerce (Sinden et al., 1984). Assuming that risk reduction, with respect to glycoalkaloids, is important for potato-based food products, the following principles should be considered for establishing substantial equivalence. Glycoalkaloid concentration in tubers of genetically modified cultivars should not exceed those of the original cultivar from which they were derived and should never be consistently above $200 \mathrm{mg} \cdot \mathrm{kg}^{-1}$ (FWB). Reduction in glycoalkaloid concentration should be considered acceptable in altered cultivars and not a basis for rejection for lack of substantial equivalence. Because of environmental variability, comparisons should be made using tubers grown at a common location.

\section{Potato constituents for which comparisons are important}

Total solids. Approximately $75 \%$ of the dry matter content of potatoes consists of starch. The remainder is composed of sugars, proteins, and assorted cell and cell wall components (Storey and Davies, 1992). In nutrition studies, one medium-sized potato, on average, provided $26 \mathrm{~g}$ of carbohydrates, $\approx 9 \%$ of the average daily value (Pennington and Wilkening, 1997). Elton (1978) reported that, at the time, potatoes provided $5.3 \%$ of the average European's energy requirement.
This makes potato starch a very important dietary item.

Dry matter is also an important factor of potato palatability and processing quality (Gould, 1980). About 65\% of the potatoes grown in the United States and Canada are processed. Potato cultivars are categorized according to dry matter content and their perceived value to the processing industry.

With respect to nutrition, total solids of genetically modified cultivars should fall within the range of commercially grown cultivars. However, because of the impact on processed food quality, if a genetically modified cultivar is to be used in the place of its original counterpart, the principles for establishing substantial equivalence should be more stringent. Total solids of genetically modified cultivars should be similar or equal to the cultivar from which they were derived. Because environment and storage temperature can influence dry matter content, comparisons should be made using potatoes produced and stored under the same conditions.

Sugars. The major sugars in potatoes, sucrose and the reducing sugars fructose and glucose, are present in small quantities and are inconsequential as a source of food energy. However, like total solids, they are a very important factor in processed food quality. When potatoes are fried, reducing sugars condense with other cell components to form dark-colored compounds that give the products a burned taste and appearance. Sucrose is only marginally important in this reaction, but serves as a reservoir for the formation of additional reducing sugars (Sowokinos and Preston, 1988).

Maintaining cultivar identity is important for sugars for the same reason it is important for total solids. Sugars of genetically modified cultivars should be similar or identical to those of cultivars from which they were derived. Because both growing environment and storage temperature have a strong influence on sugar content, comparisons should be made on tubers grown at the same location and stored under identical conditions.

\section{Potato constituents for which comparisons are desirable}

Potatoes contain measurable amounts of proteins, fats, carbohydrates, and numerous vitamins and minerals. However, they are a significant dietary source of only two of these nutritional factors, protein and vitamin C. For this reason, these are the only other nutritional constituents of potato that logically should be considered in establishing substantial equivalence of genetically modified potato cultivars.

Protein. Potatoes supply $8 \%$ to $13 \%$ of the FAO/WHO-recommended daily allowance of protein for children and 6\% to $7 \%$ for adults (Storey and Davies, 1992). Potato proteins are highly digestible and have a good balance of amino acids. They are especially high in the essential amino acid lysine. 
Agriculture Canada has applied some pressure to require amino acid analysis for genetically modified potatoes that will be used for animal feed. There is little justification for requiring this procedure as part of establishing substantial equivalence unless inserted genes code for nutritionally important amounts of a novel protein. For most modifications, this is an unlikely event, even though many genetic modifications result in the translation of new enzymes or proteins. The quantities of these novel proteins are minuscule compared to those of existing proteins. Nearly all of the proteins in potato tubers consist of albumin, globulin, glutelin, and prolamin (all considered to be classes of tuberin if derived from potatoes) (Storey and Davies, 1992). These protein fractions all have similar amino acid composition, and changes in their respective ratios will have little impact on the amino acid profile (Storey and Davies, 1992). From a nutritional perspective, measurement of total protein is a more valuable procedure than measurement of individual amino acids.

Genetically modified cultivars should be considered substantially equivalent with respect to protein when concentrations fall within the range expressed by commercially produced cultivars. There is no reason to require protein content in a genetically modified cultivar to meet the standard of being equal to that cultivar from which it was derived. Again, if testing is done, comparisons should be made using potatoes grown at the same location.

Vitamin C. Potatoes provide $45 \%$ of the daily requirements for vitamin $\mathrm{C}$ (Pennington and Wilkening, 1997). This makes them one of the better sources of vitamin C available as part of the human diet. For this reason, requiring determination of vitamin $\mathrm{C}$ as part of procedures to establish substantial equivalence may be appropriate. Principles and procedures for establishing substantial equivalence for vitamin $\mathrm{C}$ should be the same as those suggested for protein.

\section{SUMMARY}

The concept of substantial equivalence for genetically modified crops is rapidly evolving, based on precedence set during the development of the first transgenic crops. It is important at this stage to strike a balance between the cost of determination of substantial equivalence and the economical feasibility of using biotechnology for the improve- ment of minor-use horticultural crops. Potatoes provide a good illustration of the application of substantial equivalence.

Precedence set by traditional breeding and historical crop use demonstrates that nutritional and toxicological constituents requiring critical evaluation for potatoes, and probably any crop, are few in number. It also demonstrates that, in general, genetically modified cultivars need not be identical to the cultivars from which they were derived, but simply contain critical components within a historically acceptable range. Exceptions may include constituents that are an important part of cultivar identity and are critical for industry use or those having toxicological properties.

For potatoes, key constituents for establishing substantial equivalence in genetically modified cultivars include tuber glycoalkaloids, total solids, sugars (sucrose and reducing), and possibly protein and vitamin C. For glycoalkaloids, total solids, and sugars, comparisons should be made against the original cultivar from which each genetically modified cultivar was derived. Genetically modified cultivars should be equal to, or lower than their original counterparts in glycoalkaloid concentration; they should be about equal to their counterparts in total solids and sugars if processing quality is an issue and the genetically modified cultivar is to be used in the place of the original cultivar. Comparison for protein and vitamin $\mathrm{C}$ content should be made against the ranges published for all commercially accepted cultivars. A similar list of key components, their acceptable ranges, and appropriate comparisons must be established for each crop destined for human or animal consumption. By limiting the number of constituents that are considered critical and broadening acceptable parameters for equivalence, one portion of research costs can be held at an affordable level.

Maintaining food safety is important in agricultural research. The concept of substantial equivalence provides a good basis for ensuring food safety in genetically modified crop cultivars. However, it can also be a major factor in increasing the price of products derived through biotechnology above the consumer's willingness to pay. Therefore, a common-sense approach should be used for determination of substantial equivalence, especially for the sake of minor-use horticultural crops. This will require a list of essential constituents for each crop, as well as, a compilation of appropriate ranges of variation to serve as comparatives.

\section{Literature Cited}

Chase, R.W., 1992. North American potato cultivar inventory. Potato Assn. of Amer., Orono, Me.

Elton, G.A.H. 1978. European diets in relation to standards of need, p. 25-40. In: J. Yudkin (ed.). Diet of men: Needs and wants. Applied Sci., London.

FAO/WHO. 1991. Strategies for assessing the safety of foods produced by biotechnology. Report of a joint FAO/WHO consultation. World Health Organization, Geneva.

Gould, W.A. 1980. Quality control procedures for the manufacture of potato chips and snack foods. Potato Chip/Snack Food Assn., Alexandria, Va.

Lavrik, P.B. and S.L. Love. 1994. Composition and quality analysis of potato tubers derived from field-grown Colorado potato beetleresistant potato plants. Monsanto Co. Study Rpt. No. 92-01-37-19.

Murphy, E.F., R.H. True, and J.M. Hogan. 1967. Detection threshold of sensory panels for mealiness of baked potatoes as related to specific gravity differences. Amer. Potato J. 44:442-451.

Pennington, J.A.T. and V.L. Wilkening. 1997. Final regulations for the nutrition labeling of raw fruits, vegetables, and fish. J. Amer. Dietetic Assn. 97:1299-1305.

Sinden, S.L. 1991. Suggested guidelines on tuber glycoalkaloid contents (TGA) for potato breeders. Rpt. Potato Assn. of Amer., Breeding and Genet. Section. USDA/ARS Veg. Lab., Beltsville, Md.

Sinden, S.L., L.L. Sanford, and R.E. Webb. 1984. Genetic and environmental control of potato glycoalkaloids. Amer. Potato J. 61:141-156.

Sowokinos, J.R. and D.A. Preston. 1988. Maintenance of potato processing quality by chemical maturity monitoring (CMM). Univ. Minnesota Agr. Expt. Sta. Bul. 586-1988.

Storey, R.M.J. and H.V. Davies. 1992. Tuber quality, p. 504-544. In: P.M. Harris (ed.), The potato crop: The scientific basis for improvement. Chapman and Hall. London.

Talburt, W.F. 1975. History of potato processing, p. 1-11. In: W.F. Talburt and O. Smith (eds.). Potato processing. AVI, Westport, Conn.

Van Gelder, W.M.J. 1991. Steroidal glycoalkaloids in Solanum: Consequences for potato breeding and food safety, p. 101-134. In: R.F. Keeler and A.T. Tu (eds.). Handbook of natural toxins Vol. 6, Toxicology of plant and fungal compounds. Marcel Dekker, New York.

Zitnak, A. 1977. Steroids and capsaicinoids of Solanaceous food plants, p. 41-91. In: N.F. Childers and G.M. Russo (eds.). The nightshades and health. Somerset Press, Somerville, N.J. 